\title{
Erythropoietin-Mediated Secretion of Transforming Growth Factor $\beta 1$ by Bone Marrow Mononuclear Cells is Negatively Regulated by Granulocytes via Secretion of Erythropoietin Receptors in the Milieu.
}

\section{Vaijayanti Prakash Kale ( $\sim$ vaijayanti.kale@ssbs.edu.in )}

Symbiosis International University https://orcid.org/0000-0001-7498-7563

\section{Research Article}

Keywords: TGF 31 , EPO, EPO-R, Soluble EPO-R, CD15+ granulocytes, CD2+ T lymphocytes,

Posted Date: August 20th, 2021

DOl: https://doi.org/10.21203/rs.3.rs-807581/v1

License: (9) This work is licensed under a Creative Commons Attribution 4.0 International License. Read Full License 


\section{Abstract}

In our previous study, we demonstrated that bone marrow-derived mononuclear cells (BM MNCs) secrete copious amounts of Transforming Growth Factor $\beta 1$ (TGF $\beta 1$ ) in response to erythropoietin (EPO). In this study, we investigated the principal cell type involved in the process. We found that a large percentage of various marrow cells, but not their mature counterparts present in the peripheral blood, express EPO-R. Cell depletion experiments showed that removing Glycophorin positive erythroblasts and CD $41^{+}$ megakaryocytes - the prime suspects - did not affect the EPO-mediated TGF $\beta 1$ secretion by the BM MNCs. However, individual depletion of $\mathrm{CD} 2^{+} \mathrm{T}$ lymphocytes, $\mathrm{CD} 14^{+}$monocyte/macrophages, and $\mathrm{CD} 19^{+}$ $B$ cells affected the TGF $\beta 1$ secretion by EPO-primed MNCs: depletion of CD2 ${ }^{+}$cells had the most striking effect. Unexpectedly, and most interestingly, depletion of $C D 15^{+}$granulocytes led to a significant increase in the TGF $\beta 1$ secretion by both naïve and EPO-primed BM MNCs, suggesting that these cells negatively regulate the process. Mechanistically, we show that the $\mathrm{CD} 15^{+}$cells exert this regulatory effect via secretion of both full-length and soluble EPO-R in the milieu. Overall our results, for the first time, unravel an in-built regulatory mechanism prevailing in the $\mathrm{BM}$ microenvironment that regulates the secretion of TGF $\beta 1$ by controlling EPO-EPO-R interaction.

Our data could be relevant in understanding the pathophysiology of several conditions associated with deregulated production of TGF $\beta 1$ in the marrow compartment.

\section{Introduction}

Transforming Growth Factor beta 1 (TGF $\beta 1$ ) is a pleiotropic cytokine, acting positively and negatively depending on its concentration or the target cell involved [1,2,3]. Earlier, we have shown that it boosts the hematopoietic supportive ability of human mesenchymal stromal cells [MSCs; 4]. It plays a vital role in maintaining the quiescence of hematopoietic stem cells [HSCs; 5,6$]$. We have recently demonstrated that TGF $\beta 1$ significantly accelerates terminal stages of erythroid differentiation by promoting BNIP3L/NIXmediated mitophagy [7]. On the other hand, it is a cause of several pathological conditions such as marrow fibrosis $[8,9,10]$.

Erythropoietin (EPO) acts via its cognate receptor (EPO-R) present on erythroblasts to generate red blood cells. However, recent literature shows that in addition to erythroid progenitors, functional EPO-R is also expressed by several other types of hematopoietic cells, including $T$ and $B$ lymphocytes and monocytes $[11,12,13]$, immature dendritic cells [14], erythroblastic island macrophages [15], osteoclasts and osteoblasts [16, 17], so on and so forth. Expression of EPO-R in non-erythroid tissues such as brain, kidney, heart, vascular endothelium, has also been reported. In these tissues, it primarily acts as a major tissue-protective survival factor by reducing apoptotic cell death [18].

Our previous study demonstrated that bone marrow mononuclear cells (BM MNCs) secrete TGF $\beta 1$ in response to EPO [4], partly explaining its presence at the active sites of hematopoiesis. In the present study, we endeavored to identify the cell type involved in the process. We found that secretion of TGF $\beta 1$ 
by BM MNCs in response to EPO is perhaps collectively mediated by $C D 2^{+} \mathrm{T}$ cells, $\mathrm{CD} 19^{+} \mathrm{B}$ cells, and $\mathrm{CD} 14^{+}$monocyte/macrophage cells, but critically depends on the presence of $\mathrm{CD} 2^{+} \mathrm{T}$ cells. Most interestingly, we found that $\mathrm{CD} 15^{+}$granulocytes negatively regulate this process by constitutively secreting both full-length and soluble EPO-R in the milieu.

To the best of our knowledge, ours is the first report, which unravels an inbuilt regulatory mechanism prevailing in the BM microenvironment that regulates the secretion of TGF $\beta 1$ by controlling EPO-EPO-R interaction. Our data could be relevant in understanding the pathophysiology of several pathological conditions that are known to be associated with deregulated production of TGF $\beta 1$ in the marrow compartment.

\section{Material And Methods}

\section{Reagents}

Iscove's Modified Dulbecco's Medium(IMDM) was from HiMedia (Mumbai, India), Fetal Bovine Serum (FBS) was from Invitrogen, MA, USA; anti-Glycophorin A and B (raised in mouse), FITC-tagged anti-rabbit antibody (raised in goat), Collagenase Type 1A, EPO, TGF $\beta 1$, protease and phosphatase inhibitor cocktails and Histopaque were from Sigma-Aldrich (MO, USA); recombinant human soluble EPO-R and anti-EPO-R antibodies (raised in mouse and goat) were from R\&D Systems (MN, USA); anti-EPO-R antibody raised in rabbit and its corresponding neutralizing peptide, and anti-TGF $\beta 1$ antibodies (raised in mouse and rabbit) were from Santacruz Biotech (TX, USA); anti-biotin-HRP and anti-rabbit IgG-HRP antibodies were from Cell Signalling Technology (MA, USA), antibodies to CD41a and CD41b were from Pharmingen ( CA, USA); all tissue culture grade plastic ware was from Nunc/Thermo Fisher Scientific ( MA, USA); and microfuge tubes were from Eppendorf (Hamburg, Germany). TGF $\beta 1$ ELISA kit was from Genzyme (MA, USA). Dynabeads ${ }^{\circledR}$ immunomagnetic beads conjugated to antibodies to CD2, CD4, CD8, CD14, CD15, CD19, and anti-mouse IgG were from Invitrogen/Thermo Fisher Scientific (MA, USA). All flow-qualified antibodies (Table S1), their respective isotypes, and Human BD FC block were from Beckton Dickinson (Franklin Lakes, NJ, USA). Protein A/G agarose was from Thermo Fisher, Scientific (MA, USA). PVDF membrane (Sequiblot) was from Biorad (CA, USA). LumiGLO ${ }^{\text {TM }}$ substrate was from (Cell Signaling Technology).

\section{Isolation of Bone Marrow and peripheral blood mononuclear cells:}

Left-over iliac crest pieces from grafts used in spine surgeries were collected in IMDM supplemented with $2 \%$ FBS and cut into small pieces. The pieces were subjected to collagenase (Type $1 \mathrm{~A} ; 1 \mathrm{mg} / \mathrm{ml}$ prepared in IMDM) digestion for 15 minutes at room temperature with constant gentle stirring. The dissociated cells were collected by centrifugation, washed twice with plain IMDM, and MNCs were isolated using density-gradient centrifugation using Histopaque. The MNCs were suspended in $1 \mathrm{ml}$ of complete growth medium (IMDM supplemented with $20 \%$ FBS) or cell isolation buffer (1X PBS supplemented with 1\%BSA and $0.6 \%$ Sodium citrate, $\mathrm{pH}$ 7.4). Viable cell count was taken using Trypan Blue, and the cell suspension 
was adjusted to $1 \times 10^{7} \mathrm{MNCs} / \mathrm{ml}$ using the growth medium or cell isolation buffer as required for the experiment. Cell viability was typically $\geq 95 \%$.

$10 \mathrm{ml}$ of peripheral blood samples were collected from healthy volunteers, and mononuclear cells were isolated using a density gradient centrifugation using Histopaque. The cells were washed and processed for flow cytometry analysis.

\section{Detection of EPO-R on BM and PBL MNCs by flow cytometry}

MNCs (BM or PBL) were suspended $\left(5 \times 10^{6}\right.$ cells $\left./ \mathrm{ml}\right)$ in $1 \%$ BSA-PBS supplemented with $0.01 \%$ sodium

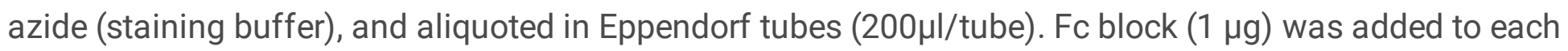
tube, and the tubes were incubated for 20 minutes at RT. The tubes were cooled on ice, and $1 \mu \mathrm{g} / \mathrm{ml}$ antiEPO-R antibody (raised in rabbit) was added. After incubation on ice for 45 minutes with intermittent mixing, the cells were washed and suspended in the staining buffer. PE-tagged antibodies to specific cell surface markers (or their isotypes) (TableS1) and the FITC-tagged anti-rabbit antibody were added (all $1 \mu \mathrm{g} / \mathrm{ml}$ ) in all tubes. The cells were incubated for 45 minutes on ice with intermittent mixing. The cells were washed, suspended in sheath fluid, and immediately acquired on a flow cytometer (Cantoll, BD). \% EPO- $\mathrm{R}^{+}$cells present in a particular lineage was determined.

\section{Depletion of specific cell types:}

One $\mathrm{ml}$ of BM MNCs suspended in pre-cooled isolation buffer $\left(1 \times 10^{7} \mathrm{MNCs} / \mathrm{ml}\right)$ were kept on ice, and $100 \mu$ of pre-washed paramagnetic beads tagged to specific antibodies were added to them. This ratio of cells to beads was standardized by flow analysis of the depleted population using specific antibodies. The cells and beads were mixed by gentle tapping and gently inverting the tubes a few times.

For depletion of glycophorin ${ }^{+}$erythroblasts and $\mathrm{CD} 41^{+}$megakaryocytes, a two-step procedure was followed. First, the cells were incubated with antibodies to glycophorin a and b, or CD41 a and b (raised in mouse, $2 \mu \mathrm{g}$ each) for 45 minutes on ice, followed by washing. Then $100 \mu \mathrm{l}$ of paramagnetic beads tagged to anti-mouse IgG were added to each tube to deplete the positive cells.

The tubes were incubated on ice for 45 minutes with intermittent tapping. The tubes were then held on a magnet for 2 minutes to allow the cells attached to the beads to settle. Supernatant unbound cells were collected, washed, and suspended in one $\mathrm{ml}$ of complete growth medium. These cells were labeled as $C D \star \star$-dep MNCs, depending on the antibody used (e.g. CD2-dep MNCs). Equivalent cell suspension (1 ml) of un-manipulated MNCs was used as controls (undep MNCs).

\section{Preparation of Conditioned media (CM):}

BM MNCs $\left(1 \times 10^{7} / \mathrm{ml}\right)$, depleted of specific cell type or not, were incubated in the growth medium with or without the addition of EPO $(2 \mathrm{U} / \mathrm{ml})$. After 48 hours, the cells were harvested and centrifuged at $3000 \mathrm{rpm}$ in a cold centrifuge. The cells were suspended in the growth medium and incubated for a further 24 hrs. 
without the addition of EPO. In the experiments involving immune-precipitation of TGF $\beta 1$, this second step was performed in a serum-free medium. The cell-free supernatants (conditioned medium, $\mathrm{CM}$ ) were collected and aliquoted in polypropylene microfuge tubes. Aliquots were stored at $-80^{\circ} \mathrm{C}$ till further use. An equal amount of growth medium was also incubated in parallel and aliquoted.

\section{Quantification of TGF $\beta 1$ in the CM}

CM preparations were subjected to ELISA assay using Genzyme TGF 31 ELISA kit as per the manufacturer's instructions. A standard curve was generated using purified TGF $\beta 1$ supplied with the kit. Readings for only growth medium (IMDM supplemented with 20\% FBS, incubated for 48 hrs.) were subtracted from the readings obtained for $\mathrm{CM}$ preparations.

\section{Immuno-precipitation of CM}

Aliquots of $\mathrm{CM}$ were precleared using protein $\mathrm{A} / \mathrm{G}$ agarose and then subjected to immune-precipitation using anti-EPO-R or anti-TGF $\beta 1$ antibodies $(5 \mu \mathrm{g} / 500 \mu \mathrm{l}$ each, raised in mouse and rabbit, respectively). The immune-precipitate was dissolved in $30 \mu$ of lysis buffer, boiled in sample buffer at $95^{\circ} \mathrm{C}$ for 5 minutes, and subjected to western blot analysis using anti-EPO-R or anti-TGF $\beta 1$ antibodies (raised in goat and mouse, respectively). The IP of TGF $\beta 1$ and rTGF $\beta 1$ were boiled in the sample buffer prepared without the addition of 2-ME.

\section{Western blot}

The samples were electrophoretically separated on polyacrylamide gel containing SDS (SDS PAGE). The separated proteins were then electrically transferred onto PVDF membrane (Sequiblot, Biorad). The membranes were blocked with 5\%BSA prepared in TBST (Tris-buffered saline supplemented with $0.1 \%$ Tween 20), for 3 hours, washed thrice with TBST, and probed with antibodies to EPO-R or TGF 11 followed by incubation with appropriate HRP-conjugated secondary antibodies (Cell Signaling Technology). Immuno-reactive conjugates were detected using LumiGLO ${ }^{\text {TM }}$ substrate (Cell Signaling Technology) according to the manufacturer's instructions.

\section{Statistical Analysis}

Data are expressed as mean \pm SD. Statistical significance of all data was analyzed by One-Way Repeated Measure Analysis of Variance (One-Way RM ANOVA) using Sigma Stat software version 3.5 (Jandel Scientific, CA, USA) and is denoted as ${ }^{*} p \geq 0.5,{ }^{*} \geq 0.01,{ }^{* *} \geq p 0.001$. The distribution of data was examined for normality using the Shapiro-Wilk normality test.

\section{Results}

Expression of EPO-R by BM MNCs. 
To detect the expression of EPO-R on various types of cells present in the bone marrow, we performed flow cytometry analyses of BM MNCs using lineage-specific antibodies together with an antibody to EPOR. We performed a similar analysis of MNCs isolated from peripheral blood (PBL). We found that a large percentage of various BM cells analyzed expressed EPO-R, albeit at variable levels (Fig. 1, Table S2, Fig. $\mathrm{S} 1)$. The percentage of EPO- $\mathrm{R}^{+}$cells, as well as mean fluorescence intensity (MFI) of EPO-R, were the highest in $\mathrm{GP}^{+}$erythroblasts ( $>80 \%$; MFI $\left.1,06,412\right)$ - as expected - and, surprisingly, also in $\mathrm{CD} 15^{+}$ granulocytes (>90\%; MFI 1,02,557).

On the other hand, except for the $\mathrm{GP}^{+}$erythroblasts - which were present in the minority in PBL MNCs (0.5-1.5\%) - a tiny, almost negligible, percentage of other cell types from peripheral blood-derived MNCs expressed EPO-R (Table S2), suggesting that perhaps EPO-R expression is lost during the maturation process in cells other than erythroid lineage cells.

\section{Identification of cell type(s) involved in EPO-mediated TGF $\beta 1$ secretion by BM MNCs}

Since various BM MNCs analyzed showed the expression of EPO-R, it was necessary to examine the contribution of each cell type in their EPO-mediated production of TGF $\beta 1$. Here we took an approach of immuno-magnetic depletion of individual cell types and quantified the amount of TGF $\beta 1$ secreted by the "specific cell-depleted population" in response to EPO.

First, we examined the effect of depletion of $\mathrm{GP}^{+}$erythrocytes - the known target of EPO, and CD $41^{+}$ megakaryocytes (MKs) - known to secrete TGF $\beta 1$ [19]. Contrary to our expectation, we found that individual depletion of these cells did not affect the amount of TGF $\beta 1$ secreted by the remaining MNCs (Fig. 2A), suggesting that perhaps these cells do not contribute to the EPO-mediated secretion of TGF $\beta 1$ (hereafter referred to as EMST for brevity) by the BM MNCs.

Then we individually depleted $\mathrm{CD} 2^{+} \mathrm{T}$ cells, $\mathrm{CD} 14^{+}$monocyte/macrophage cells, $\mathrm{CD} 15^{+}$granulocytes and $\mathrm{CD} 19^{+} \mathrm{B}$ cells from the MNCs, treated the remaining cells with EPO, and quantified the TGF $\beta 1$ levels in the respective CMs. As seen in Fig. 2B and Fig. 2C, individual depletion of CD2 ${ }^{+}$T lymphocytes, CD $14^{+}$ monocyte/macrophage, and CD19+ $B$ cells decreased the EMST significantly: the most drastic effect was seen with the depletion of $C D 2^{+} T$ cells (Fig. 2B, C; compare 3rd bar with 2 nd bar). Most interestingly, we found that depletion of $\mathrm{CD} 15^{+}$cells resulted in a significant increase in TGF $\beta 1$ production by the remaining MNCs (CD15-dep-E) over their EPO-treated undepleted (undep-E) counterparts (Fig. 2B, C, compare 5th bar with 2nd bar, respectively).

We then examined the effect of individual depletion of $\mathrm{CD} 4^{+}$helper T cells and CD8 ${ }^{+}$suppressor $\mathrm{T}$ cells on the process. In this set, we also kept their respective unprimed controls to see whether a mere depletion of $T$ cell subsets affects the basal level secretion of TGF 1 by the remaining MNCs. Individual depletion of $\mathrm{CD} 2^{+}, \mathrm{CD} 4^{+}$, or $\mathrm{CD} 8^{+}$cells did not affect the basal level secretion of TGF $\beta 1$ by the remaining MNCs (Fig. 2D; compare 1st bar with 3rd ,5th and 7th bars). However, as seen in the previous experiments, depletion of $\mathrm{CD} 2^{+}$cells, but not of $\mathrm{CD} 4^{+}$cells, resulted in a significant drop in the EMST 
(Fig. 2D; compare 2nd bar with 4th and 6th bars). Depletion of CD8 ${ }^{+} \mathrm{T}$ cells resulted in a marginal but significant increase in the EMST (Fig. 2D; compare 2nd and 8th bars). The mechanistic of this aspect needs to be studied further.

Collectively, these data show that EMST is a highly complex process that is positively and negatively regulated by various types of marrow cells.

\section{Dose-dependent EMST by the CD15-depleted MNCs.}

A significant increase in the TGF $\beta 1$ secretion by CD $15^{+}$-dep MNCs was a very intriguing finding, and hence, we decided to study this phenomenon further. First, we examined whether CD15-depleted MNCs respond to EPO in a dose-dependent fashion. CD15+dep-MNCs and undep-MNCs were exposed, or not, to various concentrations of EPO $(1,2$, and $5 \mathrm{IU} / \mathrm{ml})$, and the CM preparations were subjected to ELISA. We found that CD15-dep MNCs responded to EPO in a dose-dependent manner by secreting higher amounts of TGF $\beta 1$ with a corresponding increase in EPO (Fig. 3A). As seen in our previous experiments [4], the EPO-primed undep MNCs showed a dose-dependent increase in the TGF $\beta 1$ secretion up to $2 \mathrm{IU} / \mathrm{ml}$ of EPO, but this level remained steady even when the EPO concentration was raised to $5 \mathrm{IU} / \mathrm{ml}$.

Interestingly, the CM of unprimed (0 IU/ml) CD15-dep MNCs contained a much higher level of TGF $\beta 1$, as compared to its undep-control counterpart (Fig. 3A), suggesting that $C D 15^{+}$cells negatively regulate TGF $\beta 1$ secretion of both, unprimed as well as EPO-primed BM MNCs.

We then subjected the CM (prepared in a serum-free medium) of both, unprimed and EPO-primed CD15dep MNCs to immune-precipitation using an antibody to TGF $\beta 1$ (raised in rabbit) and western blot analyses to detect TGF $\beta 1$ (blot probed with an antibody raised in mouse). IPs from medium and recombinant human TGF $\beta 1$ ( $\mathrm{rTGF} \beta 1 ; 5 \mathrm{ng}$ ) were loaded as the negative and positive control, respectively. As seen in Fig. 3B, CM of both, CD15-dep-C and CD15-dep-E cells showed clear bands of TGF $\beta 1$, which corresponded to the band of rTGF $\beta 1$. As seen in the ELISA experiments, a much larger amount of TGF $\beta 1$ could be immune-precipitated from the CM of EPO-primed CD15-dep MNCs compared to that from CM of unprimed CD15-dep MNCs.

\section{Granulocytes negatively regulate EMST by BM MNCs by secreting both full-length and soluble forms of EPO-R in the milieu.}

Our earlier study shows that soluble EPO-R interferes with the EMST by BM MNCs [4]. Hence, we hypothesized that perhaps $\mathrm{CD} 15^{+}$cells negatively regulate EMST by BM MNCs by secreting SEPO-R in the milieu. To examine this possibility, we incubated the CM preparations of CD15 $5^{+}$cells (unprimed and EPOprimed) with an antibody to EPO-R (raised in mouse) and subjected the immuno-precipitate to western blot analysis using another antibody to EPO-R (raised in goat). Recombinant sEPO-R (10ng) was also loaded on the gel to serve as a positive control. Surprisingly, we found that $C D 15^{+}$cells not only secreted the soluble EPO-R, as postulated but also the full-length EPO-R in the medium (Fig. 3C). The amount of secreted full-length EPO-R with or without EPO was similar, whereas there was a slight increase in the 
level of sEPO-R in the EPO-primed CM (Fig. 3C). Pre-incubation of the probing antibody with sEPO-R abrogated the signal confirming the specificity (Fig. 3D).

The data suggest that $\mathrm{CD} 15^{+}$cells control EMST by the BM MNCs via secretion of both full-length and soluble EPO-R in the milieu: full-length EPO-R would directly quench EPO present in the milieu, while SEPO-R would act as a decoy receptor for EPO, and interfere with the action of EPO that has escaped the quenching process.

For the first time, these data reveal the importance of granulocytes in the regulation of hematopoiesis by restricting the secretion of a negative regulator in the BM environment. These data could have immense implications in clinical settings.

\section{Discussion}

Erythropoietin is an essential hormone for erythropoiesis, but its actions on non-erythroid cells are also known [20]. EPO functions by binding to and activating its cognate receptor, EPO-R, though non-EPO-Rmediated actions have also been reported [21]. We have recently demonstrated that BM MNCs secrete copious amounts of TGF $\beta 1$ when primed with EPO [4]. A small amount of EPO is constitutively present in the circulation ( $5 \mathrm{pM} ; 20 \mathrm{mU} / \mathrm{mL} ; 100 \mathrm{pg} / \mathrm{mL}$ ), and its level increases in response to hypoxia [22], hence it is logical to assume that a natural in-built mechanism must be operative in vivo to control excessive production of TGF $\beta 1$ in response to elevated levels of EPO. Presently, these mechanisms are not known. Here we report a novel finding that secretion of TGF $\beta 1$ by BM MNCs in response to EPO critically depends on the presence of $\mathrm{CD} 2^{+} \mathrm{T}$ cells, and $\mathrm{CD} 15^{+}$Granulocytes negatively regulate the process. Mechanistically, for the first time, we show that granulocytes control both basal level and EPO-mediated TGF $\beta 1$ secretion (EMST) by BM MNCs via secretion of both, full-length and soluble forms of EPO-R in the milieu.

In addition to erythroid progenitors, several other types of hematopoietic cells such as $\mathrm{T}$ and $\mathrm{B}$ lymphocytes and monocytes express EPO-R $[11,12,13]$. Here we show that a significant $\%$ of $T$ and $B$ lymphocytes, monocytes, and granulocytes present in the bone marrow express EPO-R. Interestingly, a meager percentage of peripheral blood counterparts of all these cells expressed EPO-R. Our data point towards a possibility that the loss of expression of EPO-R is perhaps a marker of progressive commitment and differentiation. This exciting possibility needs to be formally examined. To the best of our knowledge, ours is perhaps the first study showing a differential expression of EPO-R on BM and PBL MNCs.

EPO-R has also been detected on leukemic cells in several cases of acute myeloblastic leukemia (AML) and acute lymphoblastic leukemia (ALL) and distributed widely among all FAB-subtypes. However, in vitro proliferative response to EPO has not been observed in these cases [23]. Hence, the significance of EPO-R on leukemic cells remained unclear. Based on our data, we speculate that BM cells perhaps progressively lose the EPO-R expression as a function of differentiation. Since leukemic cells are arrested at various stages of differentiation, it would be interesting to examine whether knock-down of EPO-R in these cells 
would push them towards differentiation. If proved to be so, this approach could yield an adjunct therapeutic approach for leukemia treatment. We are investigating this aspect.

The cellular composition of bone marrow is constant under steady-state conditions; however, it could vary under conditions like infection, chemotherapy, or myeloablation. Our data suggest that such changes, mainly involving changes in the numbers of $\mathrm{CD} 2^{+} \mathrm{T}$ cells or $\mathrm{CD} 15^{+}$granulocytes, could result in a deregulated production of TGF $\beta 1$, and these changes could have systemic consequences. This possibility needs to be examined using BM samples from patients showing abnormal marrow cellularity. In this context, the $\mathrm{CD} 15^{+}$granulocyte-mediated negative regulation of TGF $\beta 1$ appears to have direct physiological relevance. Granulocytes play an essential role in the defense against pathogens. Their loss during pre-conditioning used in transplants poses a big risk for the transplanted patients [24]. Unexpectedly, and most interestingly, we found that these cells express EPO-R on their surface at a high density, and shed both full-length and soluble EPO-R in the milieu. Depleting these cells resulted in a significant increase in the level of TGF $\beta 1$ even in the absence of EPO. Interestingly, the secretion of TGF $\beta 1$ by CD15-dep MNCs showed a linear increase in response to higher concentrations of EPO, as against that by the un-depleted MNCs, which reached a plateau at a higher concentration of EPO. These data clearly show that perhaps granulocytes act as an in-built mechanism in the BM to guard against excessive production of TGF $\beta 1$, and their loss could result in uncontrolled production of TGF $\beta 1$ in the BM microenvironment leading to unwarranted consequences.

The term granulocyte encompasses neutrophils, basophils, and eosinophils, amongst which neutrophils form the major subset hence, we assume that neutrophils primarily mediate the observed response. Neutropenia is frequently associated with marrow fibrosis caused by TGF $\beta 1[8,9,10]$. Our data provide a possible explanation for this phenomenon. We have already shown that soluble EPO-R interferes with the secretion of TGF $\beta 1$ by BM MNCs [4]. Thus, therapeutic use of soluble EPO-R or a function-blocking peptide could prevent the marrow fibrosis associated with these conditions. This concept needs to be formally examined using suitable experimental models so that it can be applied clinically.

Peripheral blood T cells, B cells, and macrophages have been shown to express EPO-R on their surface and are known to produce TGF $\beta 1$ in response to EPO [11,25, 26]. On the other hand, Lifshitz et al., [27] and Prutchi-Sagiv et al. [28] did not detect EPO-R on PBL lymphocytes, and their results agree with ours. In our study also, we found that the \% of EPO-R-expressing T cells, B cells, and monocyte-macrophage present in the PBL was insignificant compared with that in their counterparts in BM. Such differences could perhaps arise due to technical differences amongst various studies.

CD2 is a costimulatory receptor expressed mainly on T cells, but it is also expressed on NK cells [29]. In the present study, we have not examined the effect of specific depletion of NK cells, which might also get depleted by CD2-conjugated immunomagnetic beads. Both T cells and NK cells may be needed for the EMST by BM MNCs. This possibility needs to be examined. TGF $\beta 1$ is known to be involved in both suppressive and inflammatory immune responses [30]. Likewise, EPO is also known to be involved in immune regulation [31] via binding to the heterodimer of EPO-R/ $\beta C R$, known as tissue-protective receptor 
(TPR). Therefore, it will be interesting to examine whether EMST is also mediated via TPR and whether it is involved in immune regulation.

When we individually depleted $\mathrm{CD} 4^{+}$and $\mathrm{CD} 8^{+}$cells, we found that the removal of $\mathrm{CD} 4^{+}$cells did not affect the EMST, but the removal of $\mathrm{CD}^{+}$cells resulted in a marginal, but significant, increase in EMST, suggesting that perhaps, like granulocytes, these cells also have some negative regulatory effect on the process. In this study, we have not examined the mechanistic involved in this aspect, but we propose to do so in the near future. Nonetheless, ours is perhaps the first report showing that CD2 ${ }^{+}$cells present in the BM play a positive regulatory role in the "multi-cellular" response to EPO.

\section{Summary}

In summary, we demonstrate that EPO-mediated secretion of TGF $\beta 1$ by the marrow cells is a complex multi-cellular phenomenon that critically depends on the presence of $\mathrm{CD}^{+} \mathrm{T}$ cells, and granulocytes negatively regulate the process by secreting of both full-length and soluble EPO-R in the milieu. These findings could have implications in several pathological conditions known to be caused by deregulated production of TGF $\beta 1$. Our data have unraveled a novel role of granulocytes in controlling the TGF $\beta 1$ levels in the marrow compartment.

\section{Abbreviations}

BM - Bone marrow

PBL - Peripheral blood-derived leukocytes

EPO - Erythropoietin

EPO-R - Erythropoietin Receptor

IMDM - Iscove's Modified Dulbecco's Medium

FBS - Fetal Bovine Serum

MNC - Mononuclear Cells

TGF $\beta 1$ - Transforming Growth Factor beta 1

2-ME - 2-Mercaptoethanol

EMST - EPO-mediated secretion of TGF $\beta 1$

\section{Declarations}




\section{Acknowledgements}

The author wishes to thank National Centre for Cell Science (DBT-NCCS), Pune, India, and Symbiosis Centre for Research \& Innovation, Symbiosis International (Deemed University), Pune, India, for funding and providing infrastructural support, respectively; Dr. Charudatta Apte, Sahyadri Hospital, Pune, India for providing iliac crest samples; Dr. L.C. Padhy, ex-scientist, TIFR, Mumbai, India, for insightful discussions and generous sharing of reagents; and flow cytometry facility of DBT-NCCS for sample acquisition.

\section{Availability of Data and materials}

The article and its supplementary information files contain all data generated or analyzed during this study.

\section{Author's contribution}

Vaijayanti Kale: Conceptualization, Methodology, Investigation, Validation, Formal Analysis and investigation, Resources, Writing - original draft preparation and Reviewing \& Editing, Project Administration, Funding Acquisition.

\section{Funding}

This study was funded by an intramural grant by National Centre for Cell Science, (DBT-NCCS), Pune, India.

\section{Compliance with Ethical standards}

\section{Conflict of interest}

The author declares no conflict of interest.

The author has no relevant financial or non-financial interests to disclose

\section{Ethics approval}

The study was approved by the Institutional Ethics Committee (IEC) and Institutional Committee for Stem Cell Research (IC-SCR) of National Centre for Cell Science (NCCS), Pune and certify that the study was performed in accordance with the ethical standards as laid down in the 1964 Declaration of Helsinki and its later amendments or comparable ethical standards. Informed consent was obtained from all individual participants included in the study.

\section{References}

1. Kale V. P. (2004). Differential activation of MAPK signaling pathways by TGF-beta 1 forms the molecular mechanism behind its dose-dependent bidirectional effects on hematopoiesis. Stem cells 
and development, 13(1), 27-38. https://doi.org/10.1089/154732804773099236

2. Kale, V. P., \& Vaidya, A. A. (2004). Molecular mechanisms behind the dose-dependent differential activation of MAPK pathways induced by transforming growth factor-beta1 in hematopoietic cells. Stem cells and development, 13(5), 536-547. https://doi.org/10.1089/scd.2004.13.536

3. Blank, U., \& Karlsson, S. (2015). TGF- $\beta$ signaling in the control of hematopoietic stem cells. Blood, 125(23), 3542-3550. https://doi.org/10.1182/blood-2014-12-618090

4. Kale V. P. (2020). Transforming growth factor- $\beta$ boosts the functionality of human bone marrowderived mesenchymal stromal cells. Cell biology international, 44(11), 2293-2306. https://doi.org/10.1002/cbin.11437

5. Wang, X., Dong, F., Zhang, S., Yang, W., Yu, W., Wang, Z., Zhang, S., Wang, J., Ma, S., Wu, P., Gao, Y., Dong, J., Tang, F., Cheng, T., \& Ema, H. (2018). TGF- $\beta 1$ Negatively Regulates the Number and Function of Hematopoietic Stem Cells. Stem cell reports, 11(1), 274-287. https://doi.org/10.1016/j.stemcr.2018.05.017

6. Naka, K., \& Hirao, A. (2017). Regulation of Hematopoiesis and Hematological Disease by TGF- $\beta$ Family Signaling Molecules. Cold Spring Harbor perspectives in biology, 9(9), a027987. https://doi.org/10.1101/cshperspect.a027987

7. Kuhikar, R., Khan, N., Philip, J., Melinkeri, S., Kale, V., \& Limaye, L. (2020). Transforming growth factor $\beta 1$ accelerates and enhances in vitro red blood cell formation from hematopoietic stem cells by stimulating mitophagy. Stem cell research \& therapy, 11(1), 71. https://doi.org/10.1186/s13287-02001603-z

8. Rameshwar, P., Chang, V. T., Thacker, U. F., \& Gascón, P. (1998). Systemic transforming growth factorbeta in patients with bone marrow fibrosis-pathophysiological implications. American journal of hematology, 59(2), 133-142. https://doi.org/10.1002/(sici)1096-8652(199810)59:2<133::aidajh6>3.0.co;2-z

9. Chagraoui, H., Komura, E., Tulliez, M., Giraudier, S., Vainchenker, W., \& Wendling, F. (2002). Prominent role of TGF-beta 1 in thrombopoietin-induced myelofibrosis in mice. Blood, 100(10), 3495-3503. https://doi.org/10.1182/blood-2002-04-1133

10. Agarwal, A., Morrone, K., Bartenstein, M., Zhao, Z. J., Verma, A., \& Goel, S. (2016). Bone marrow fibrosis in primary myelofibrosis: pathogenic mechanisms and the role of TGF- $\beta$. Stem cell investigation, 3, 5. https://doi.org/10.3978/j.issn.2306-9759.2016.02.03

11. Lisowska, K. A., Debska-Slizień, A., Bryl, E., Rutkowski, B., \& Witkowski, J. M. (2010). Erythropoietin receptor is expressed on human peripheral blood $T$ and $B$ lymphocytes and monocytes and is modulated by recombinant human erythropoietin treatment. Artificial organs, 34(8), 654-662. https://doi.org/10.1111/j.1525-1594.2009.00948.x

12. Lisowska, K. A., Bryl, E., \& Witkowski, J. M. (2011). Erythropoietin receptor is detectable on peripheral blood lymphocytes and its expression increases in activated T lymphocytes. Haematologica, 96(3), e12-e14. https://doi.org/10.3324/haematol.2010.038414 
13. Deshet-Unger, N., Kolomansky, A., Ben-Califa, N., Hiram-Bab, S., Gilboa, D., Liron, T., Ibrahim, M., Awida, Z., Gorodov, A., Oster, H. S., Mittelman, M., Rauner, M., Wielockx, B., Gabet, Y., \& Neumann, D. (2020). Erythropoietin receptor in B cells plays a role in bone remodeling in mice. Theranostics, 10(19), 8744-8756. https://doi.org/10.7150/thno.45845

14. Rocchetta, F., Solini, S., Mister, M., Mele, C., Cassis, P., Noris, M., Remuzzi, G., \& Aiello, S. (2011). Erythropoietin enhances immunostimulatory properties of immature dendritic cells. Clinical and experimental immunology, 165(2), 202-210. https://doi.org/10.1111/j.1365-2249.2011.04417.x

15. Li, W., Wang, Y., Zhao, H., Zhang, H., Xu, Y., Wang, S., Guo, X., Huang, Y., Zhang, S., Han, Y., Wu, X., Rice, C. M., Huang, G., Gallagher, P. G., Mendelson, A., Yazdanbakhsh, K., Liu, J., Chen, L., \& An, X. (2019). Identification and transcriptome analysis of erythroblastic island macrophages. Blood, 134(5), 480491. https://doi.org/10.1182/blood.2019000430

16. Lappin, K. M., Mills, K. I., \& Lappin, T. R. (2021). Erythropoietin in bone homeostasis-Implications for efficacious anemia therapy. Stem cells translational medicine, 10(6), 836-843. https://doi.org/10.1002/sctm.20-0387

17. McGee, S. J., Havens, A. M., Shiozawa, Y., Jung, Y., \& Taichman, R. S. (2012). Effects of erythropoietin on the bone microenvironment. Growth factors (Chur, Switzerland), 30(1), 22-28. https://doi.org/10.3109/08977194.2011.637034

18. Arcasoy M. O. (2008). The non-haematopoietic biological effects of erythropoietin. British journal of haematology, 141(1), 14-31. https://doi.org/10.1111/j.1365-2141.2008.07014.x

19. Gong, Y., Zhao, M., Yang, W., Gao, A., Yin, X., Hu, L., Wang, X., Xu, J., Hao, S., Cheng, T., \& Cheng, H. (2018). Megakaryocyte-derived excessive transforming growth factor $\beta 1$ inhibits proliferation of normal hematopoietic stem cells in acute myeloid leukemia. Experimental hematology, 60, 40-46.e2. https://doi.org/10.1016/j.exphem.2017.12.01

20. Arcasoy M. O. (2010). Non-erythroid effects of erythropoietin. Haematologica, 95(11), 1803-1805. https://doi.org/10.3324/haematol.2010.030213

21. Elliott, S., Busse, L., Swift, S., McCaffery, I., Rossi, J., Kassner, P., \& Begley, C. G. (2012). Lack of expression and function of erythropoietin receptors in the kidney. Nephrology, dialysis, transplantation : official publication of the European Dialysis and Transplant Association - European Renal Association, 27(7), 2733-2745. https://doi.org/10.1093/ndt/gfr698

22. Elliott, S., \& Sinclair, A. M. (2012). The effect of erythropoietin on normal and neoplastic cells. Biologics : targets \& therapy, 6, 163-189. https://doi.org/10.2147/BTT.S32281

23. Takeshita, A., Shinjo, K., Naito, K., Ohnishi, K., Higuchi, M., \& Ohno, R. (2002). Erythropoietin receptor in myelodysplastic syndrome and leukemia. Leukemia \& lymphoma, 43(2), 261-264. https://doi.org/10.1080/10428190290006026

24. Celebi, H., Akan, H., Akçağlayan, E., Ustün, C., \& Arat, M. (2000). Febrile neutropenia in allogeneic and autologous peripheral blood stem cell transplantation and conventional chemotherapy for malignancies. Bone marrow transplantation, 26(2), 211-214.

https://doi.org/10.1038/sj.bmt.1702503

Page $13 / 18$ 
25. Lisowska, K. A., Bryl, E., \& Witkowski, J. M. (2011). Erythropoietin receptor is detectable on peripheral blood lymphocytes and its expression increases in activated T lymphocytes. Haematologica, 96(3), e12-e14. https://doi.org/10.3324/haematol.2010.038414

26. Mausberg, A. K., Meyer Zu Hörste, G., Dehmel, T., Stettner, M., Lehmann, H. C., Sheikh, K. A., \& Kieseier, B. C. (2011). Erythropoietin ameliorates rat experimental autoimmune neuritis by inducing transforming growth factor- $\beta$ in macrophages. PloS one, 6(10), e26280. https://doi.org/10.1371/journal.pone.0026280

27. Lifshitz, L., Tabak, G., Gassmann, M., Mittelman, M., \& Neumann, D. (2010). Macrophages as novel target cells for erythropoietin. Haematologica, 95(11), 1823-1831.

https://doi.org/10.3324/haematol.2010.025015

28. Prutchi-Sagiv, S., Golishevsky, N., Oster, H. S., Katz, O., Cohen, A., Naparstek, E., Neumann, D., \& Mittelman, M. (2006). Erythropoietin treatment in advanced multiple myeloma is associated with improved immunological functions: could it be beneficial in early disease?. British journal of haematology, 135(5), 660-672. https://doi.org/10.1111/j.1365-2141.2006.06366.x

29. Binder, C., Cvetkovski, F., Sellberg, F., Berg, S., Paternina Visbal, H., Sachs, D. H., Berglund, E., \& Berglund, D. (2020). CD2 Immunobiology. Frontiers in immunology, 11, 1090. https://doi.org/10.3389/fimmu.2020.01090

30. Sanjabi, S., Oh, S. A., \& Li, M. O. (2017). Regulation of the Immune Response by TGF- $\beta$ : From Conception to Autoimmunity and Infection. Cold Spring Harbor perspectives in biology, 9(6), a022236. https://doi.org/10.1101/cshperspect.a022236Peng et al., 2020 Cell Death and Disease

31. Peng, B., Kong, G., Yang, C., \& Ming, Y. (2020). Erythropoietin and its derivatives: from tissue protection to immune regulation. Cell death \& disease, 11(2), 79. https://doi.org/10.1038/s41419020-2276-8

\section{Figures}


Figure 1
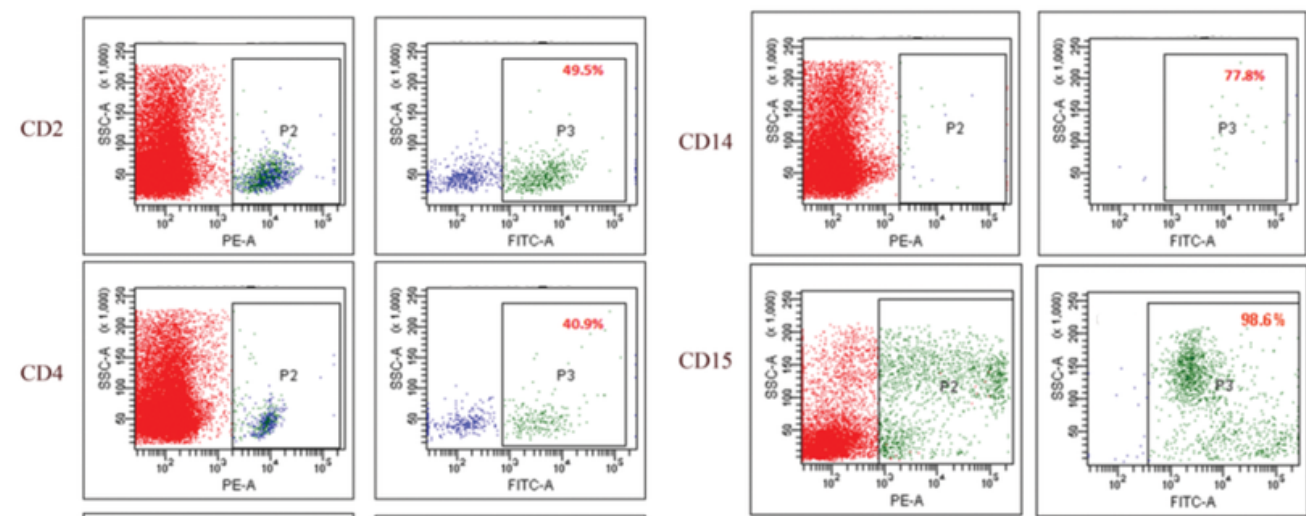

CD41

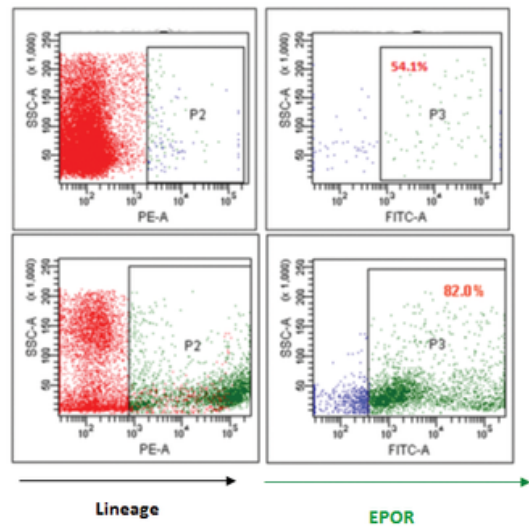

CD8
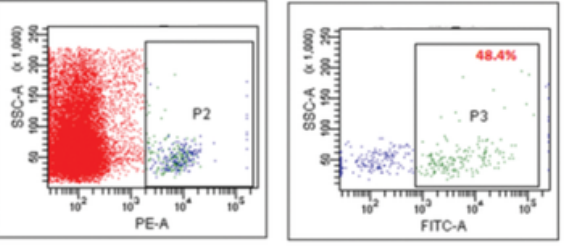

CD19
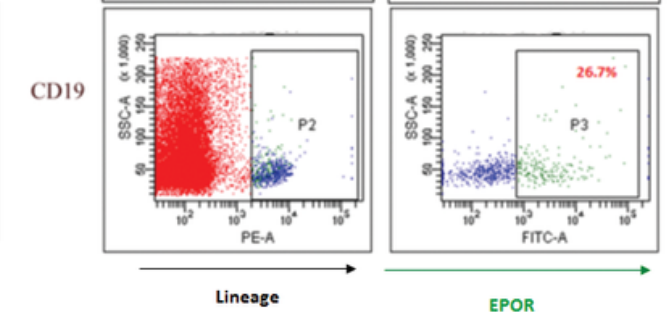

GP

\section{Figure 1}

EPO-R expression by BM MNCs. The image illustrates the flow cytometry analysis of EPO-R expression on various bone marrow cells. \% of EPO-R+ cells in the gated lineage marker-expressing cells was determined. The image shows data from one representative experiment. The experiment was repeated twice with similar results. Also, see Figure S1 and Table S2. 
Figure 2
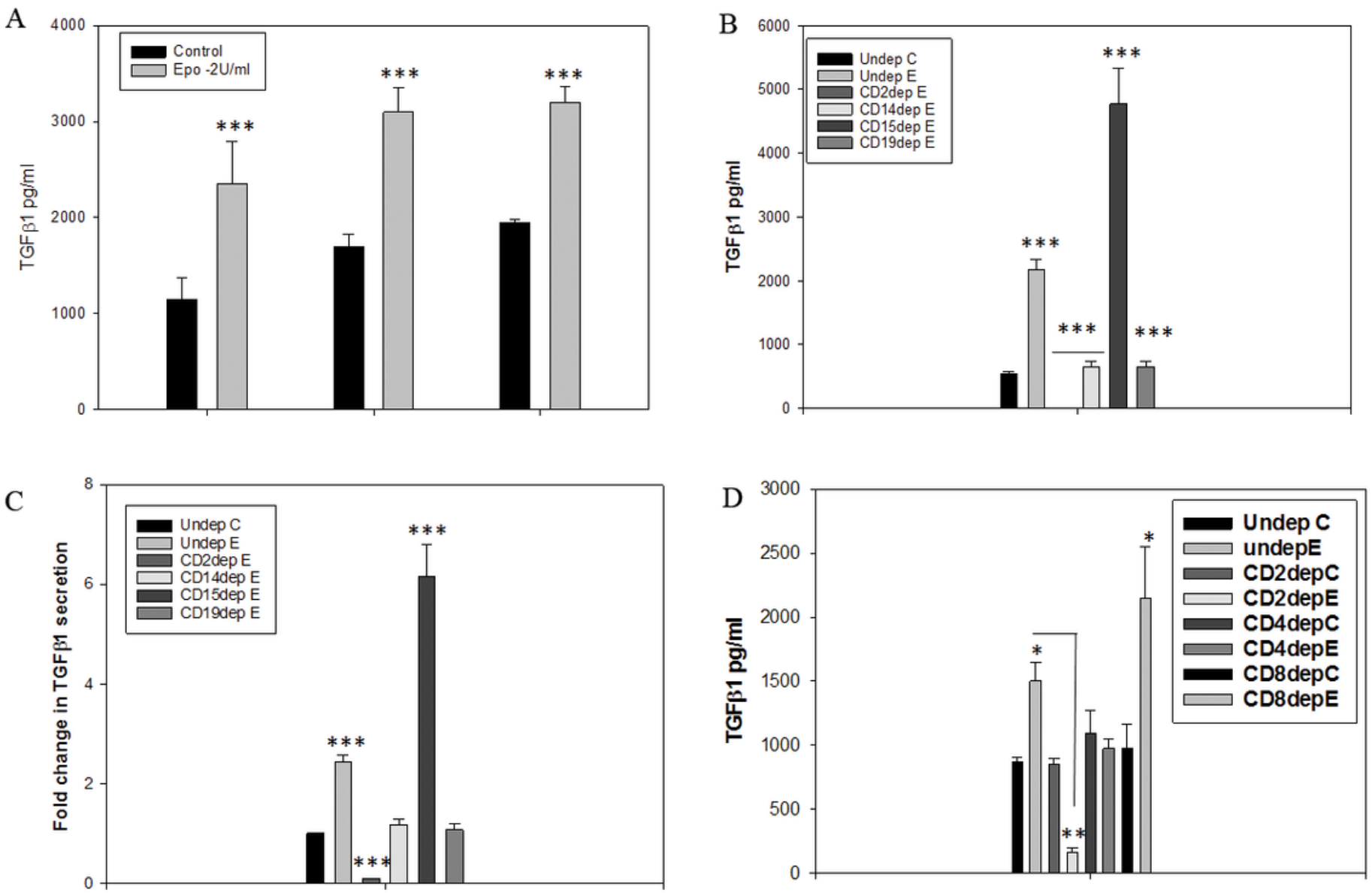

Figure 2

CD2+T cells and CD15+ granulocytes regulate EPO-mediated secretion of TGF $\beta 1$ (EMST) by BM -MNCs. The effect of depletion of specific cell types on EMST by BM MNCs was examined. Individual cell types were immuno-magnetically depleted from the BM MNCs, and the remaining cells were incubated with EPO (2 IU/ml). Unmanipulated (undepleted) MNCs, treated or not with EPO, were used as controls. The resultant CMs were analyzed by ELISA to determine TGF $\beta 1$ content in them. Mean \pm SD of 6 replicates $(n=6)$ was determined. (A) Effect of individual depletion of Glycophorin (GP)+ erythroblasts and CD41+ megakaryocytes on EMST is shown $(n=6)$. The data are from one representative experiment out of two independent experiments performed $(N=2, n=6$ in each). (B, C) Effect of individual depletion of CD2+ $T$ cells, CD14+ monocyte/macrophage, CD15+ granulocytes, and CD19+ B cells on EMST, compared to undepleted BM MNCs, has been graphically shown. Panel B shows the mean \pm SD of data obtained in one representative experiment $(n=6)$, and panel $C$ shows the mean \pm SD of data obtained in three experiments performed using three independent BM samples ( $N=3, n=6$ in each). (D) Effect of individual depletion of CD2+, CD4+ and CD8+ T cells on EMST has been graphically depicted. The graph shows the mean \pm SD of data obtained in a representative experiment $(n=6)$ out of two experiments performed using two independent BM samples ( $N=2, n=6$ in each). ${ }^{*} p \leq 0.05,{ }^{* *} p \leq 0.01,{ }^{* *} p \leq 0.001$. 
Figure 3

A

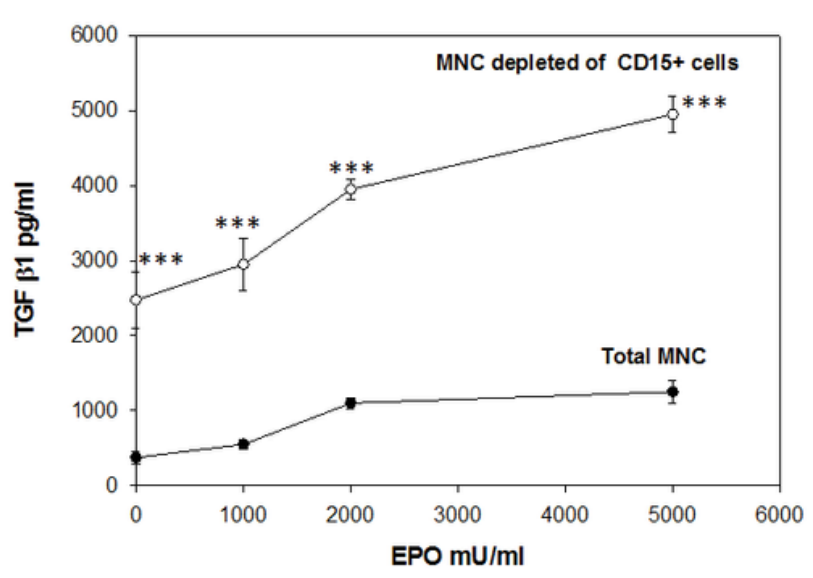

C IP anti EPO-R mouse

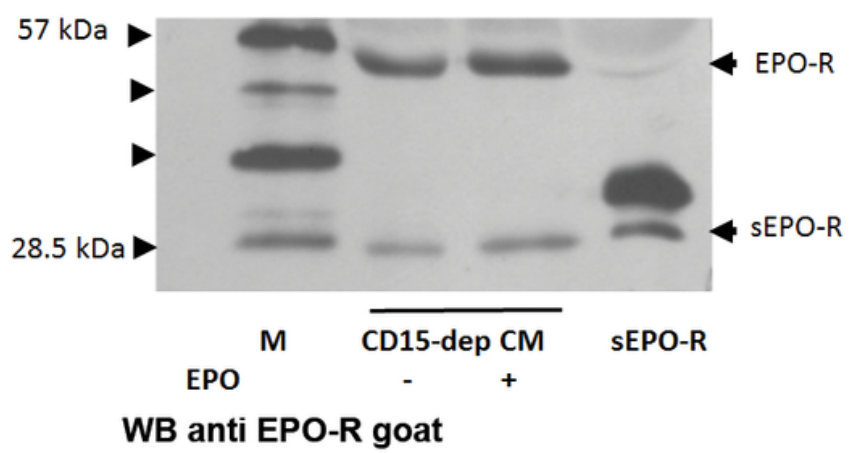

B

IP anti TGF rabbit poly

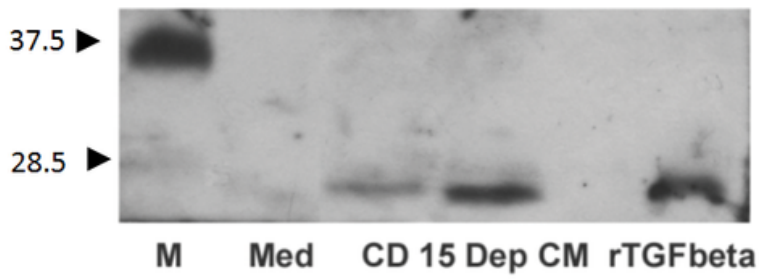

EPO 2U/ml

D

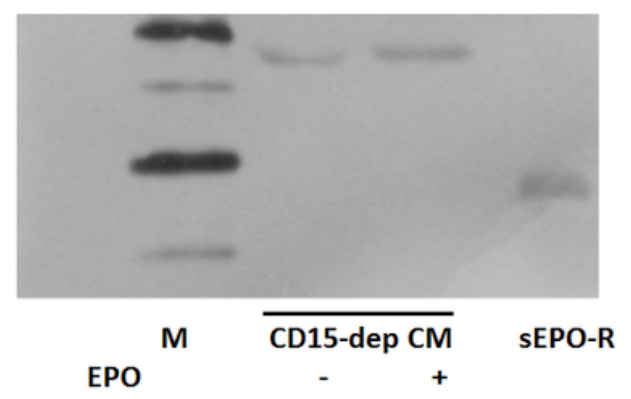

\section{Figure 3}

Granulocytes regulate EMST by BM MNCs via secretion of both full-length and soluble EPO-R. (A) The graph shows the dose-dependent secretion of TGFB1 by CD15-dep BM MNCs and undepleted MNCs. (B) CM preparations (prepared in serum-free media) of CD15 dep BM MNCs, treated or not with EPO (2 $\mathrm{IU} / \mathrm{ml}$ ), were subjected to immune-precipitation using an antibody to TGF $\beta 1$ (raised in rabbit). The IP was subjected to western blot analysis. IP from medium and recombinant TGF $\beta 1$ (both boiled in sample buffer prepared without 2-ME) were used as negative and positive controls, respectively. The blot was probed with an antibody to TGF $\beta 1$ (raised in mouse). (C) CM preparations of CD15 dep BM MNCs, treated or not with EPO $(2 \mathrm{lU} / \mathrm{ml})$, were subjected to immune-precipitation using an antibody to EPO-R (raised in mouse) and subjected to western blot analysis. Recombinant soluble EPO-R was also loaded to serve as a positive control. The blot was probed with an antibody to EPO-R (raised in goat). The higher molecular weight band seen in the lane of sEPO-R could be its glycosylated form. (D) The signal got abrogated when the probing antibody was quenched with recombinant soluble EPO-R, confirming the specificity.

\section{Supplementary Files}

This is a list of supplementary files associated with this preprint. Click to download. 
- KaleGraphicalabstract.pptx

- Figures1.tif

- KaleTableS1.docx

- KaleTables2.doc 